\title{
The Measurements of Physical Parameter on Room Acoustics: Considerations about Variability
}

\author{
Vincenzo Vodola \\ Department of Architecture, University of Bologna \\ Via Cavalcavia 61, 47521 Cesena, Italy \\ vincenzo.vodola2@unibo.it
}

\begin{abstract}
The evaluation of room acoustics characteristics in rooms has been thoroughly described in several papers since the 60-is. Moreover, the ISO 3382 standard describes several acoustic parameters and their measurements. However, there is only a few information about the methods of pre-processing the impulse responses that are required before calculating those acoustic parameters.

If the final goal of measuring the acoustical behaviour of a room is to compare it to others or to create databases, reliable and comparable data must be obtained, no matter the way they have been measured.

At the Engineering Department of the University of Bologna, several tests, with the same starting data set, have been performed to compare the results given by the most commonly used PC applications, in order to identify and quantify any possible incongruity.

In this paper, the main processing methods (based on Lundeby, Chu) are analysed. Moreover, they are compared with the Schroeder (backward integration) methods. In a further step, these methods are applied in some acoustic measurements employed in some opera houses in Italy.
\end{abstract}

Keywords: Impulse Response, Acoustical Parameters, Uncertainties, Comparisons, Different techniques.

\section{Introduction}

Accuracy of measurements is a crucial issue related to many fields of engineering studies from validation of simulated results [1] to verification of designed retrofitting scenarios [2]. Building sector is deeply investigated by in-situ measurements in order to get actual behaviour of installed components [3] compared to nominal value assumed in the simulation software [4]. Research and Development activities must rely on verified results [5] and this statement has to be applied to all the disciplines involving energy, comfort and acoustics [6,7]. Indeed, the results of any acoustical parameters measuring session could likely be related to the methods and instruments utilised. Since these acoustic parameters are physical data, this uncertainty should be totally avoided, especially where innovative solutions are tested and evaluated [8,9]. It should be also noticed that the environmental condition (i.e. temperature, humidity, and airspeed) affects both the transducers (Joule effect) and the propagation medium (air) [10].

In this study how and how much these variables affect the final results is studied, and, since the PC software have become more and more relevant, an important part of these researches focused on that topic.

Such a study should be seen as a starting point for other researches, which could more deeply and widely investigate the subject. Since technology allows measuring the acoustical parameters in always better and easier ways, it is very important to focus on a standardization of the results, a need called often in energy field from simulation to real application [11,12]. Having reliable, precise, and comparable data could extend the application field of acoustical studies to several levels allowing the data collection and its analytics [13] for the improvement of innovative building components [14]. Referring to the whole building, acoustic is the main physics parameter of theatre and auditoria, where the performance of a single instrument [15] up to an orchestra takes place. Therefore, databases with a complete characterization of theatres, concerthalls or any other hall would be information sources of great value for cultural, architectural or even entertaining purposes, ensuring the indoor comfort [16] even in existing fabric where the priority is the energy saving [17]. For this purpose, the main acoustic parameter are presented together with different methods and techniques. The Bonci theatre in Cesena is chosen as case study where the measurements were taken. 


\section{Acoustic measurements}

The most commonly used procedure to calculate the main acoustical parameters is the Impulse Response (IR) method. A method easy to compare in terms of results with the simulated performance so as to link design and operation from the early stage phase [18].

The first step to catch the acoustical behaviour of a concert hall is to excite it by using a suitable sound source, which generates a particular signal (pseudo-random, or sine sweep). Then, the signals received by the microphones are processed with the inverse filter of the starting sound. This procedure, called deconvolution, allows to determine the impulse response. Then, using a specific software, it is possible to calculate the acoustical parameter requested (such as loudness, strength, reverberation, clarity, intelligibility, and spatial aspects as lateral efficiency or IACC).

These parameters can be all obtained from the impulse responses so that a complete description of the hall can be given after having measured and analysed its impulse responses in different positions. Furthermore, this is the typical test carried out in existing theatre to characterized their performance [19].

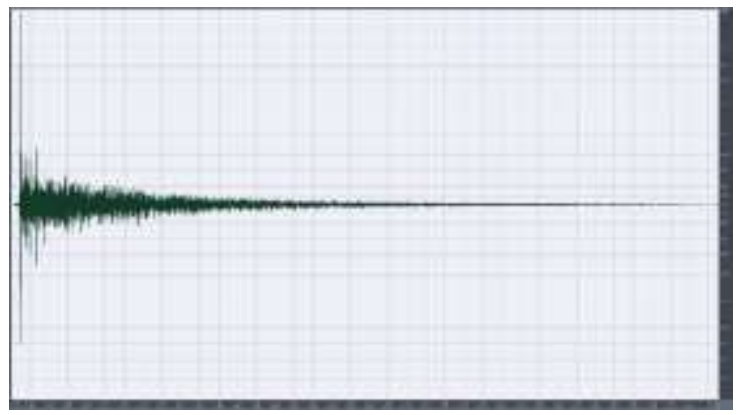

Fig. 1: Impulse Response (IR).

It is important also to point out that also impulse responses should be measured taking into account also the effect of ears on the receivers, as well as the different path propagation inside the room. Therefore, not only one impulse response is normally measured, but the so-called "binaural impulse response, BIR" (by means of a dummy head) and also the "b-format impulse response" (by means of a Soundfield probe) are measured [20].

\section{Methods' comparison}

One of the main steps of a full description of any hall involves the use of a PC application that allows measuring the parameters from an impulse response.

At the moment, there are several different software that use a different method to pre-process the IRs for calculating acoustic parameters.

Results obtained applying the Schroeder integration to a "dry" impulse response could be too sensitive to background noise and the unconstrained end of the Schroeder integration could be misleading. Different techniques have been developed to try to handle these problems [21,22]. Figure 2 shows the decay curves at $63 \mathrm{~Hz}$ and $4000 \mathrm{~Hz}$ of an impulse response. The higher signal-to-noise ratio at $4000 \mathrm{~Hz}$ permits to extract the slope of the Schroeder integral with greater confidence.

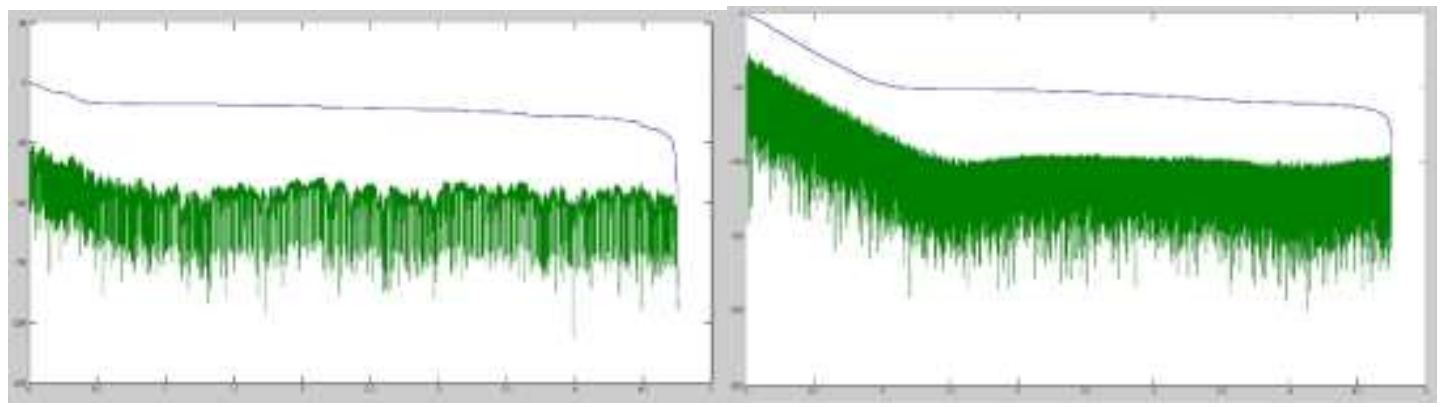

Fig. 2: Schroeder Integral and squared impulse response in $\mathrm{dB}$ scale filtered at $63 \mathrm{~Hz}$ (left) and at $4000 \mathrm{~Hz}$ (right). 
Four different software were chosen for the comparison, among the most commonly used in room acoustics measurements, namely:

- Aurora (Adobe Audition);

- WinMLS;

- Dirac;

- Sample Champion

A researcher can use any of these according to his preferences but, usually supposing that all of them give reliable results. Using the same input he should get the same outputs.

The aim of the comparison, performed at the Architecture Department of the University of Bologna, is to identify and quantify the differences between the previous applications starting from the same dataset.

Four different positions of the receivers (and therefore impulse responses) have been considered. For each of them, the acoustical parameters were calculated considering the main octave bands $(125 \mathrm{~Hz}, 250 \mathrm{~Hz}, 500 \mathrm{~Hz}, 1 \mathrm{kHz}, 2 \mathrm{kHz}$, and $4 \mathrm{kHz})$.

The parameters taken into consideration are:

- $\quad$ Clarity $(\mathrm{C} 50[\mathrm{~dB}], \mathrm{C} 80[\mathrm{~dB}])$

- Definition (D50[\%]);

- $\quad$ Reverberation Time (T30[s], EDT[s]);

- $\quad$ Lateral Fraction (LF);

- Inter-Aural Cross Correlation (IACC).

Once all these parameters were measured by means of each software, the comparison has been performed. Since the quality and the precision of the results given by the different applications were unknown, one of the software has been arbitrarily chosen as our reference. It has been selected Aurora, a plug-in for Adobe Audition, and all the results have been tabulated as deviations from the parameters obtained using this software.

\section{Comparison results}

The numerical results are affected by limitations from the software features affecting also their assessment and their mathematical post-processing [23]. As a matter of fact, it should be pointed out that not all the applications could evaluate all the parameters and it is very important from a probabilistic point of view [24], especially in historic buildings [25]. Even if the aim of the study is not to make a ranking list, these lacks affect the final judgment on some of the software. For instance, with Sample Champion is not possible to determinate the spatial quantities (Lateral Fraction and Inter-Aural Cross Correlation), whereas with Dirac it was not possible to evaluate the C50 Clarity.

Therefore, all the results have been tabulated together with the deviations from Aurora.

In the following table, it is shown an example of a comparison between the four applications considering the C80 Clarity for one of the impulse responses $(L 1)$.

It is important to notice that there are several, too high, deviations. Usually, that is due to the fact the reference value is close to zero, but, in many cases, it indicates always a very high difference between the values.

Table 1: Example of comparison.

\begin{tabular}{|c|c|c|c|c|c|c|}
\hline & $\mathbf{1 2 5}$ & $\mathbf{2 5 0}$ & $\mathbf{5 0 0}$ & $\mathbf{1 0 0 0}$ & $\mathbf{2 0 0 0}$ & $\mathbf{4 0 0 0}$ \\
\hline Aurora & 1.70 & 1.27 & 1.04 & 1.01 & 0.775 & 0.74 \\
\hline Min & 0.74 & 0.58 & 0.66 & 0.54 & 0.52 & 0.43 \\
\hline Max & 2.28 & 1.96 & 1.61 & 1.74 & 1.260 & 1.27 \\
\hline WinMLS & $6.16 \%$ & $1.95 \%$ & $1.35 \%$ & $1.83 \%$ & $1.86 \%$ & $1.13 \%$ \\
\hline var\% & $21.9 \%$ & $7.8 \%$ & $4.6 \%$ & $3.6 \%$ & $4.4 \%$ & $3.4 \%$ \\
\hline SampleC & $3.64 \%$ & $1.41 \%$ & $1.16 \%$ & $1.56 \%$ & $1.20 \%$ & $1.16 \%$ \\
\hline var\% & $8.2 \%$ & $3.8 \%$ & $3.7 \%$ & $3.4 \%$ & $3.1 \%$ & $2.71 \%$ \\
\hline Dirac & $4.09 \%$ & $4.01 \%$ & $0.90 \%$ & $1.45 \%$ & $1.04 \%$ & $1.33 \%$ \\
\hline var\% & $7.4 \%$ & $25.2 \%$ & $2.9 \%$ & $3.5 \%$ & $2.9 \%$ & $4.8 \%$ \\
\hline
\end{tabular}


Another important consideration is that sometimes the deviations from Aurora are very close for two or three software. This means that the results are similar and that Aurora is not necessarily the best application.

Therefore, it is not possible to determine, with certainty, which is the software with the most reliable performances. But, is important to emphasize that the differences between the results cannot be disregarded.

As a general trend, it is possible to see that the differences are smaller at the highest frequencies $(1000 \mathrm{~Hz}, 2000 \mathrm{~Hz}$, and $4000 \mathrm{~Hz}$ ). This is noticeable and similar for the musical instruments [26]. Other considerations can be offered to the readers looking at the single parameters (the next table shows the means of the deviations):

- For the reverberation times on high differences have been noticed; around 2\% for the EDT and something more for the T30;

- For the Definition Index, in WinMLS and Dirac small deviations were found (around 3-4\%), whereas Sample Champion gives much higher percentages (also more than 10\%);

- $\quad$ The differences are acceptable for the IACC (4-4.5\%);

For the Lateral Fraction, with both WinMLS and Dirac, the deviations grow from the high to the low frequencies $(1.5 \%$ at $4000 \mathrm{~Hz}, 2.2 \%$ at $2000 \mathrm{~Hz}, 4 \%$ at $1000 \mathrm{~Hz}, 12-13 \%$ at $500 \mathrm{~Hz}, 13-15 \%$ at $250 \mathrm{~Hz}$ and $38 \%$ at $125 \mathrm{~Hz}$ );

Table 2: Average (overall) deviations.

\begin{tabular}{|l|l|c|c|c|}
\cline { 3 - 5 } \multicolumn{2}{c|}{} & Avg & Min & Max \\
\hline \multirow{4}{*}{ EDT } & WinMLS & $2.38 \%$ & $1.13 \%$ & $6.16 \%$ \\
\cline { 2 - 5 } & SampleC. & $1.69 \%$ & $1.16 \%$ & $3.64 \%$ \\
\cline { 2 - 5 } & Dirac & $2.14 \%$ & $0.90 \%$ & $4.09 \%$ \\
\hline \multirow{4}{*}{ D30 } & WinMLS & $6.55 \%$ & $1.47 \%$ & $18.97 \%$ \\
\cline { 2 - 5 } & SampleC. & $2.63 \%$ & $0.39 \%$ & $10.47 \%$ \\
\cline { 2 - 5 } & Dirac & $8.33 \%$ & $1.21 \%$ & $24.74 \%$ \\
\cline { 2 - 5 } & WinMLS & $3.78 \%$ & $0.84 \%$ & $12.09 \%$ \\
\cline { 2 - 5 } & SampleC. & $30.73 \%$ & $1.05 \%$ & $88.25 \%$ \\
\cline { 2 - 5 } & Dirac & $3.00 \%$ & $0.75 \%$ & $8.60 \%$ \\
\hline \multirow{3}{*}{ LACC } & WinMLS & $4.47 \%$ & $1.46 \%$ & $9.24 \%$ \\
\cline { 2 - 5 } & Dirac & $4.03 \%$ & $0.91 \%$ & $6.97 \%$ \\
\cline { 2 - 5 } & WinMLS & $12.24 \%$ & $1.63 \%$ & $38.89 \%$ \\
\cline { 2 - 5 } & Dirac & $12.18 \%$ & $1.35 \%$ & $38.61 \%$ \\
\hline
\end{tabular}

\section{Comparison between methods and techniques}

Together with the PC applications, different methods have been compared during a round robin test (figure 3) that took place at the Bonci Theatre in Cesena (Italy). Several academic teams of universities from all over Italy have performed the tests. To each team it was asked to measure the main acoustical parameters with any whished method, technique, and instrument. Datasets were organized to be handled with new analytics techniques [27].

Since the goal of this article is to show the variability introduced by software, it is sufficient to say that the deviations due to the use of different methods and instruments are similar or sometimes even smaller than the previous. 


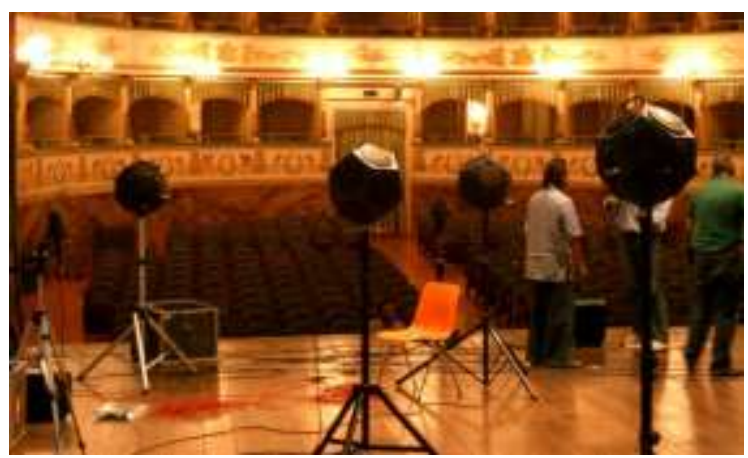

\section{Conclusion}

Fig. 3: Round robin test - Bonci Theatre.

The research on software variability has shown very meaningful results. First of all, it has been demonstrated that with almost every measured parameter the applications give substantially different results. Just for the EDT, Reverberation Time, and the IACC, (Inter-Aural Cross Correlation), the deviations are close to the perceptibility limits. For all the other parameters the variations can definitely not be disregarded and are often higher than those caused by using different methods and instruments. That is why the selection of a PC application guaranteeing realistic and accurate measurements should be seen as a crucial matter in the acoustical researches field.

It would be extremely important a deeper and wider investigation, involving researchers, users, and developers, on all the main aspects of software with the final goal of finding a standard application able to give good results. Then any other application should refer to that one, in order to have each time, with the same inputs, the same outputs

\section{Acknowledgments}

The author is in debt with Angelo Farina, for his help during the measurements and the analysis of the results.

The Authors wish to thank prof. Lamberto Tronchin for his valuable help during the development of the research. The work described in this paper was carried out within the project "Research for SEAP: a platform for municipalities taking part in the Covenant of Mayors", financed by Italian Government in the framework of PRIN 2015.

\section{References}

[1] L. C. Tagliabue, M. Manfren, A.L.C. Ciribini and E. De Angelis, "Probabilistic behavioural modeling in building performance simulation-The Brescia eLUX lab," Energy Build, vol. 128, pp. 119-131, 2016.

[2] L. De Santoli, F. Mancini, B. Nastasi and S. Ridolfi, "Energy retrofitting of dwellings from the 40's in Borgata Trullo - Rome," Energy Proc, vol. 133, pp. 281-289, 2017.

[3] U. Berardi, L. Tronchin, M. Manfren and B. Nastasi, "On the effects of variation of thermal conductivity in buildings in the Italian construction sector," Energies, vol. 11, no. 4, 872, 2018.

[4] A.L.C. Ciribini, D. Pasini, L.C. Tagliabue, M. Manfren, B. Daniotti, S. Rinaldi and E. De Angelis, “Tracking Users' Behaviors through Real-time Information in BIMs: Workflow for Interconnection in the Brescia Smart Campus Demonstrator," Proc Eng, vol. 180, pp. 1484-1494, 2017.

[5] B. Nastasi, "Hydrogen Policy, Market and R\&D Projects" in Hydrogen Production from Solar Energy, F.Calise et al., Ed. Amsterdam: Elsevier, 2019.

[6] B. Nastasi, G. Lo Basso, D.A. Garcia, F. Cumo and L. De Santoli, "Power-to-gas leverage effect on power-to-heat application for urban renewable thermal energy systems," Int. J. of Hydrogen En., vol. 43, pp. 23076-23090, 2018.

[7] L. Tronchin, "On the acoustic efficiency of road barriers: The reflection index," Int. J. Mechanics, vol. 7, no. 3, pp. 318-326, 2013.

[8] B. Castellani, E. Morini, B. Nastasi, A. Nicolini and F. Rossi, "Small-scale compressed air energy storage application for renewable energy integration in a listed building," Energies, vol. 11, no. 7, 1921, 2017.

[9] F. Scamoni, E.A. Piana and C. Scrosati, "Experimental evaluation of the sound absorption and insulation of an innovative coating through different testing methods," Build. Acous., vol. 24, no. 3, pp. 173-191, 2017.

[10] A. Farina and L. Tronchin, "3D sound characterisation in theatres employing microphone arrays," Acta Acustica United Acustica, vol. 99, no. 1, pp. 118-125, 2013. 
[11] A. Zani, L.C. Tagliabue, T. Poli, A.L.C. Ciribini, E. De Angelis and M. Manfren, "Occupancy Profile Variation Analyzed through Generative Modelling to Control Building Energy Behavior," Proc Eng, vol. 180, pp. 1495-1505, 2017.

[12] B. Castellani, S. Rinaldi, E. Morini, B. Nastasi, and F. Rossi, "Flue Gas Treatment by Power-to-Gas Integration for Methane and Ammonia Synthesis - Energy and Environmental Analysis," Energy Conv Manage, vol. 171, pp. 626634, 2018.

[13] L. Tronchin, M. Manfren and B. Nastasi, "Energy analytics for supporting built environment decarbonisation," Energy Proc, vol. 157, pp. 1486-1493, 2019.

[14] E.A. Piana, C. Petrogalli, D. Paderno and U. Carlsson, "Application of the Wave Propagation Approach to Sandwich Structures: Vibro-Acoustic Properties of Aluminum Honeycomb Materials,” Appl. Sci., vol. 8, no. 1, 45, 2018.

[15] L. Tronchin, "Modal analysis and intensity of acoustic radiation of the kettledrum," J. Acoust. Soc. Am., vol. 117, no. 2, pp. 926-933, 2005.

[16] K. Fabbri and L. Tronchin, "Indoor environmental quality in low energy buildings," Energy Proc., vol. 78, pp. 2778$2783,2015$.

[17] L. De Santoli, G. Lo Basso and B. Nastasi, "Innovative Hybrid CHP systems for high temperature heating plant in existing buildings," Energy Proc., vol. 133, pp. 207-218, 2017.

[18] L. Tronchin, M. Manfren and P.A. James, "Linking design and operation performance analysis through model calibration: Parametric assessment on a Passive House building," Energy, vol. 165, pp. 26-40, 2018.

[19] L. Tronchin, "Francesco Milizia (1725-1798) and the acoustics of his Teatro Ideale (1773)" Acta Acustica United Acustica, vol. 99, no. 1, pp. 91-97, 2013.

[20] R. Shimokura, L. Tronchin, A. Cocchi and Y. Soeta, "Subjective diffuseness of music signals convolved with binaural impulse responses," J. of Sound Vibration, vol. 330, no. 14, pp. 3526-3537, 2011.

[21] M. Barron, "Measured early lateral energy fractions in Concert Halls and Opera Houses," J. of Sound Vibration, vol. 232, no. 1, pp. 79-100, 2000.

[22] M. A. Gerzon, "Recording Concert Hall Acoustics for Posterity," J. Audio Eng. Soc., vol. 23, pp. 569-571, 1975.

[23] L. Tronchin and V.L. Coli "Further investigations in the emulation of nonlinear systems with Volterra series," AES J. Audio Eng. Soc., vol. 63, no. 9, pp. 671-683, 2015.

[24] F. Re Cecconi, M. Manfren, L.C. Tagliabue, A. L. C. Ciribini and E. De Angelis, "Probabilistic behavioral modeling in building performance simulation: A Monte Carlo approach," Energy Build, vol. 148, pp. 128-141, 2017.

[25] L. Tronchin and K. Fabbri, "Energy and microclimate simulation in a heritage building: Further studies on the Malatestiana Library," Energies, vol. 10, no. 10, pp. 1621, 2017

[26] A. Farina and L. Tronchin, "On the "Virtual" reconstruction of sound quality of trumpets," Acustica, vol. 86, no. 4, pp. 737-745, 2000.

[27] M. Manfren and B. Nastasi, "From in-situ measurement to regression and time series models: An overview of trends and prospects for building performance modelling," AIP Conference Proceedings, 2019. 